\title{
A 10-YEAR CLIMATOLOGY OF LIGHTNING FOR MACEDONIA, GREECE
}

\author{
DOI: http://dx.doi.org/10.18509/GBP.2018.08
} UDC: 551.58:551.596.5(498)"2008/2017"

\author{
Paraskevi Roupa ${ }^{1}$ \\ Theodore Karacostas ${ }^{2}$ \\ ${ }^{1}$ Hellenic National Meteorological Service, Greece \\ ${ }^{2}$ Aristotle University of Thessaloniki, Greece
}

\begin{abstract}
The Hellenic National Meteorological Service (HNMS) has operated a low - very low frequency lightning location network system since 2007. The network provides high detection efficiency with eight (8) sensors, strategically distributed across the continental and island territory of Greece. The data obtained through the "Time-Of-Arrival" method and they cover measurements of the time, location, polarity (positive or negative), peak current (in mA) of: cloud to cloud (CC), cloud to ground (CG) and ground to cloud (GC), lightning flashes.

The objective on this research is, initially to collect and analyze all the available data information of the examined 10-year (2008-2017) period for the area of Macedonia, Greece and based upon all these information to develop the lightning climatology for the area of interest by creating lightning density maps on an annual, seasonal and monthly bases of total and positive-only lightning strike activities. Moreover, climatological analyses and studies are also performed for the "warm periods" (April to September) and for the "cold periods" (October to March) of the year, in order to investigate any temporal and spatial characteristics of lightning flashes, and particularly to emphasize and focus on days with excessive lightning. It is believed that studying the aforementioned characteristics of the previous 10 years lightning events (climatology), it provides useful information about risk areas, where property or life are threatened.
\end{abstract}

Keywords: lightning climatology; lightning flashes; Macedonia - Greece.

\section{INTRODUCTION}

Lightning can be addressed as a hazard, since it kills hundreds of people every year and also as a forecasting tool, as lightning data are used to improve high-resolution forecasts of thunderstorms and convection [1, 4]. The Hellenic National Meteorological Service (HNMS) has operated a low - very low frequency lightning location network system since 2007. The system consists of eight (8) lightning sensors covering continental and island territory of Greece (Fig. 1). The sensors instantaneously detect the electromagnetic signals given off when the lightning strikes the earth's surface. The lightning network detects $\sim 95 \%$ of the overall CG activity, with its location accuracy estimated at $250 \mathrm{~m}$ [2]. The data obtained through the "Time-Of-Arrival" method cover measurements of the time, location, polarity (positive or negative), peak current (in $\mathrm{mA}$ ) of: cloud to cloud $(\mathrm{CC})$, cloud to ground (CG) and ground to cloud (GC), lightning flashes. Past national lightning climatological studies have shown a maximum of flash density over the eastern Macedonia (Kavala and Drama) [2, 5, 6, 7]. Regional lightning climatological studies 
over the area of Macedonia, Greece, are made in order to provide a detailed description of the encountered lightning activity.



Figure 1: The distribution of the eight (8) sensors of the Lightning Detection Network of the Hellenic National Meteorological Service.

\section{METHOD}

The climatology studies of the total and positive-only lightning strikes activities concern the annual, seasonal, monthly and warm and cold periods of interest. This way, the performed lightning distributions in space and time will allow lightning/thunderstorm regimes to be identified and determined. Data from 14 January 2008 to 30 November 2017 was used for all the analyses. The maps are based on a $0,1^{\circ} \times 0,1^{0}$ grid. The point data, constructed with latitudinal and longitudinal pairs with the use of a fortran program, then ingested into Matlab Software in order to create a $0,1^{\circ} \times 0,1^{\mathrm{O}}$ density analysis.

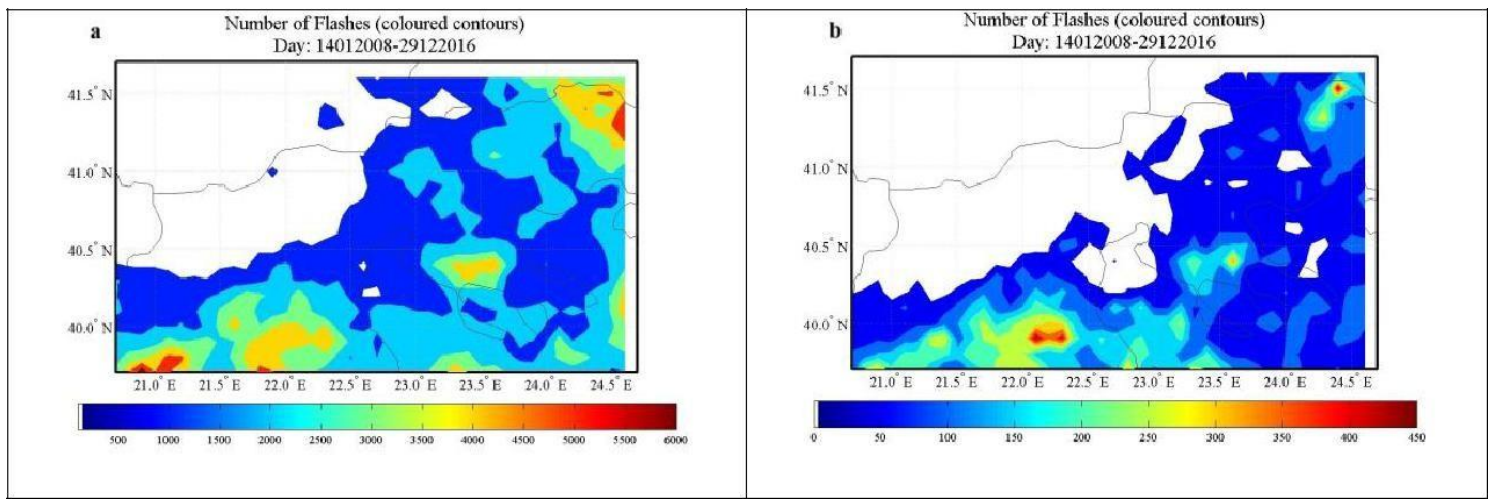

Figure 2: a) Total annual lightning density and b) total annual positive flash density. 
A total of 1.416 .934 lightning strikes were analyzed over the study period, from which the 58.808 were positive, that is only $4.15 \%$. The total annual lightning density and the total annual positive lightning density observed between 14 January 2008 and 30 November 2017 are shown in Figure 2a and Figure 2b, respectively.

Over West Macedonia, the densities are generally lower than in Central and Eastern Macedonia. The lowest densities are observed over mountain Vermio, and the highest densities occur over mountain Olympus, over mountain Holomontas, over mountain Falakro and also along the southern coastlines. In correspondence with total annual lightning, total annual positive lightning shows that the maxima are over the same regions. The annual analysis shows that lightning in Macedonia exists in areas away from the path of the Vardaris wind, which is a cold wind and has a negative forcing in surface heating. Also, land shows higher lightning densities than the waters of the Gulf of Thermaikos and the Gulf of Strimonikos.

\section{RESULTS}

The analysis of the density plots will be divided into sections for each year, each season, each month and for warm and cold periods, for total and positive-only lightning strike.

\section{Annual total lightning density}

A total of $195.511(13.8 \%)$ lightning strikes were analyzed over the study period 14-012008 to $30-12-2008$, a total of $299.163(21.1 \%)$ lightning strikes were analyzed over the study period 05-01-2009 to 28-12-2009, a total of 191.134 (13.5\%) lightning strikes were analyzed over the study period $01-01-2010$ to $31-12-2010$, a total of $129.462(9.1 \%)$ lightning strikes were analyzed over the study period 01-01-2011 to 31-12-2011, a total of 69.747 (4.9\%) lightning strikes were analyzed over the study period 01-01-2012 to 31$12-2012$, a total of $119.400(8.4 \%)$ lightning strikes were analyzed over the study period 01-01-2013 to 31-12-2013, a total of 209.621 (14.8\%) lightning strikes were analyzed over the study period 01-01-2014 to 31-12-2014, a total of $34.713(2.4 \%)$ lightning strikes were analyzed over the study period 13-01-2015 to 31-12-2015, a total of 56.355 (4.0\%) lightning strikes were analyzed over the study period 02-01-2016 to 29-12-2016 and a total of 111.828 (7.9\%) lightning strikes were analyzed over the study period 01-01-2017 to 30-11-2017. All these analyses are presented in Figure 3. The most active lightning year was the 2009, with the second most active lightning year to be the 2014, while the less active year was the 2015 . 


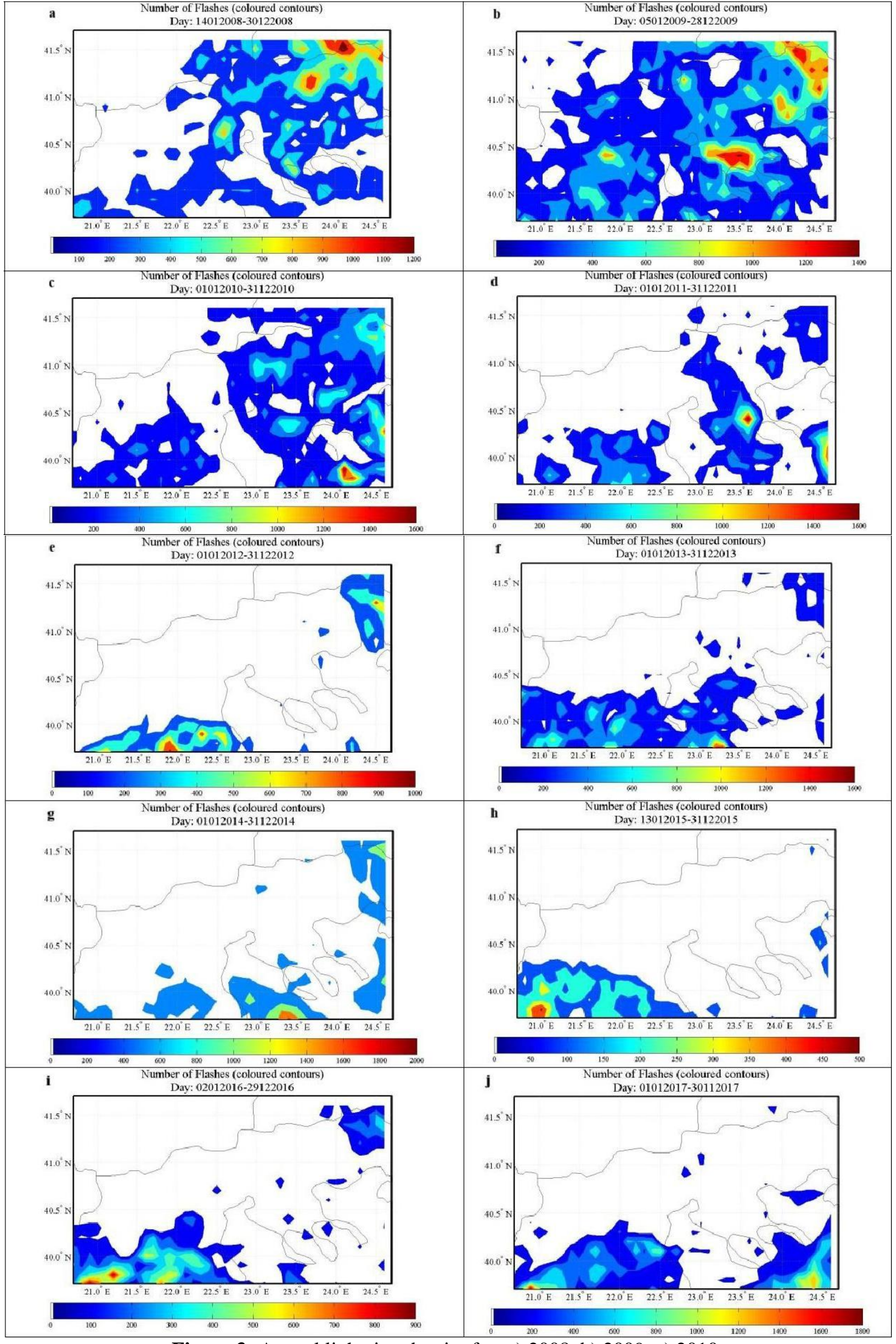

Figure 3: Annual lightning density for: a) 2008, b) 2009, c) 2010

d) 2011 , e) 2012, f) 2013, g) 2014, h) 2015, i) 2016, j) 2017. 


\section{Season total lightning density}

A total of $35.173(2.5 \%)$ lightning strikes were analyzed over the study period 14-012008 to 29-12-2016, a total of $170.262(12.0 \%)$ lightning strikes were analyzed over the study period 01-03-2008 to 27-05-2017, a total of 978.383 (69\%) lightning strikes were analyzed over the study period 01-06-2008 to 29-08-2017, a total of 233.116 (16.5\%) lightning strikes were analyzed over the study period 01-09-2008 to 30-11-2017. All these analyses are presented in Figure 5. The most active lightning season is summer, the second most active lightning season is autumn and the less active season is winter.

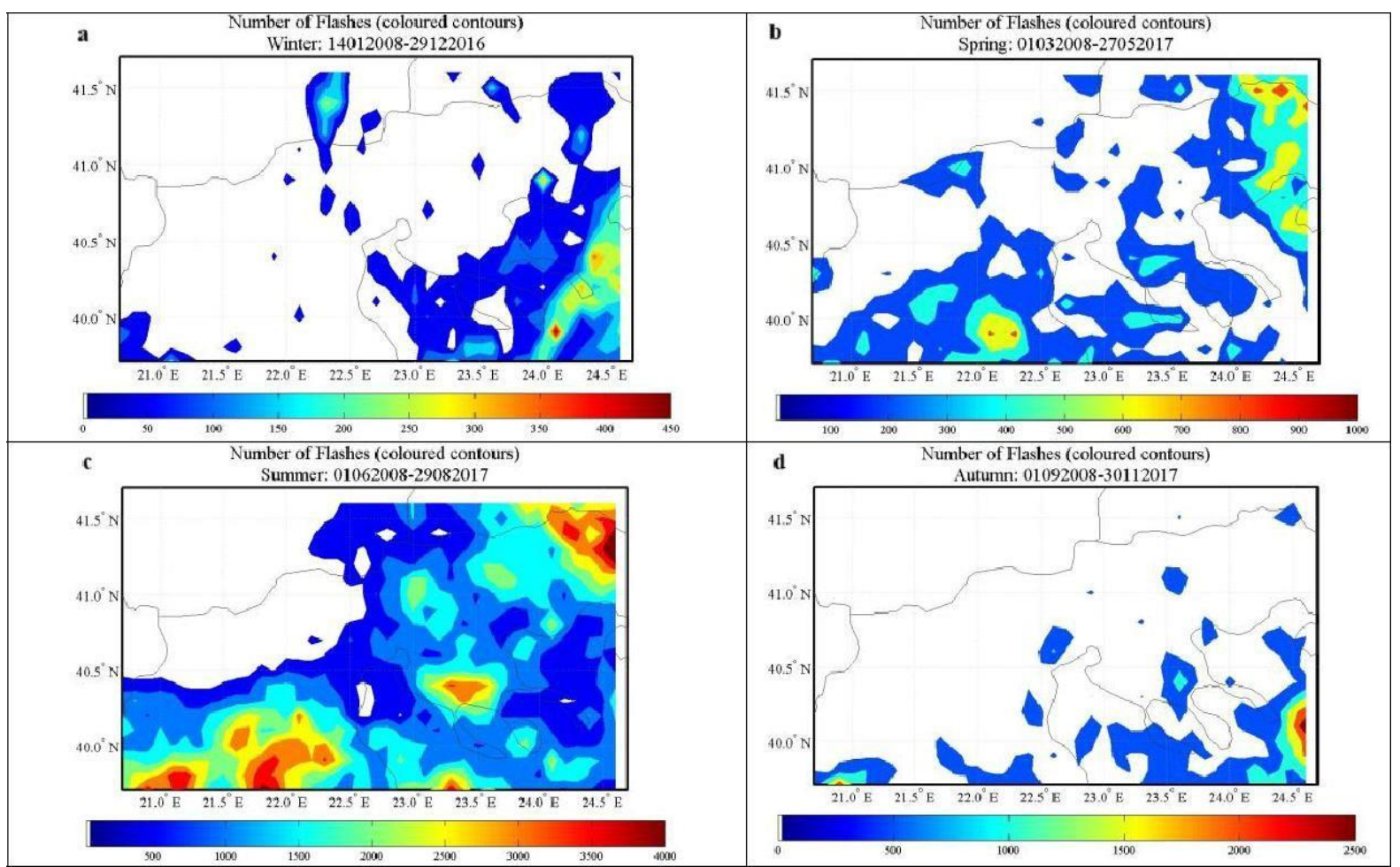

Figure 5. Season total lightning density for: a) winter, b) spring, c) summer, d) autumn.

\section{Season positive lightning density}

A total of 2.861 (4.9\%) lightning strikes were analyzed over the study period 14-01-2008 to $29-12-2016$, a total of $17.088(29.1 \%)$ lightning strikes were analyzed over the study period 02-03-2008 to 27-05-2017, a total of 28.904 (49.1\%) lightning strikes were analyzed over the study period 01-06-2008 to 29-08-2017, a total of $9.956(16.9 \%)$ 


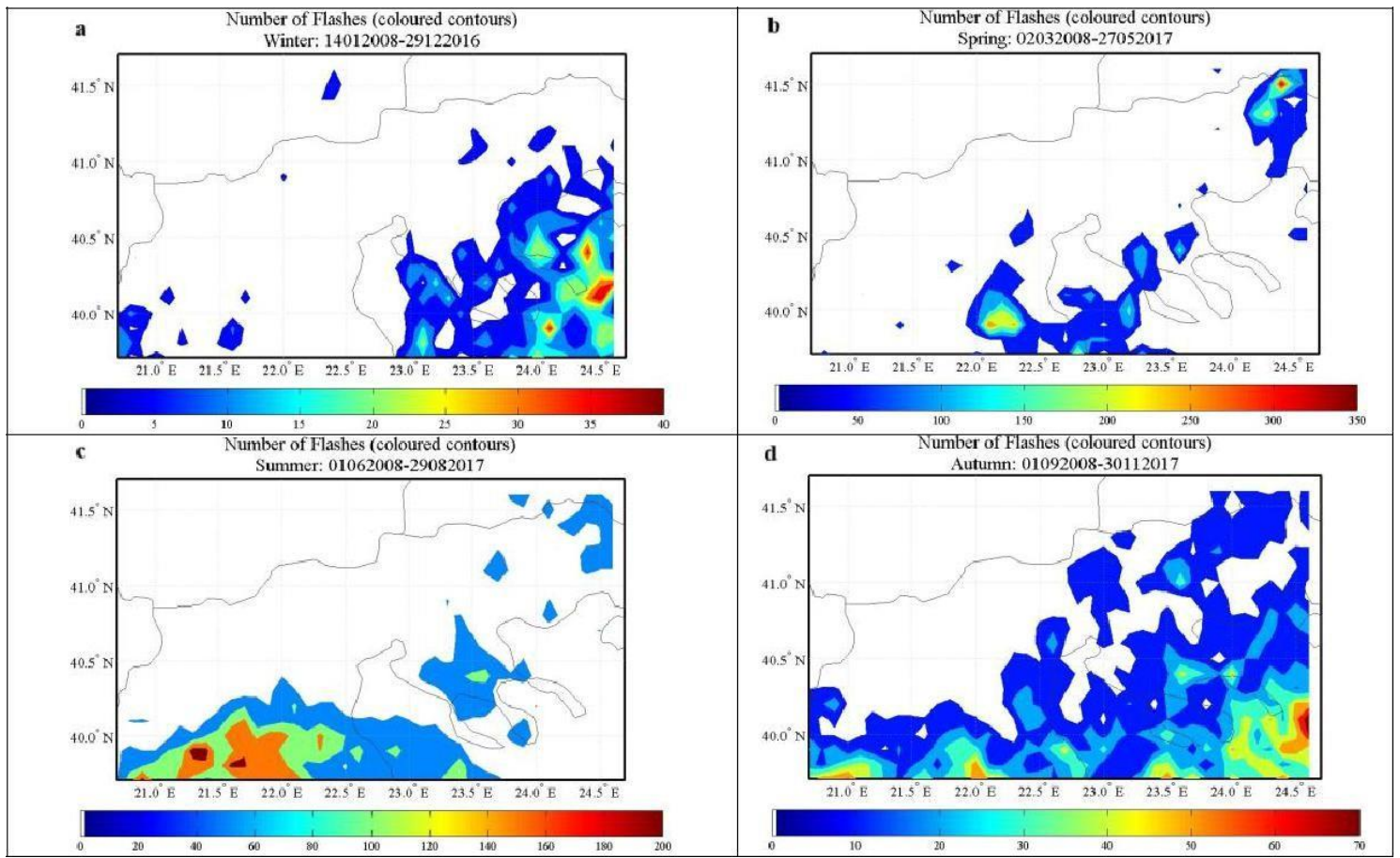

Figure 6. Season total positive lightning density for: a) winter, b) spring, c) summer, d) autumn lightning strikes were analyzed over the study period 01-09-2008 to 30-11-2017. All these analyses are presented in Figure 6 . The most active positive lightning season is summer, the second most active positive lightning season is spring and the less active season is winter.

\section{Monthly total lightning density}

A total of $5.468(0.4 \%)$ lightning strikes were analyzed over the study period 14-01-2008 to 31-01-2017, a total of $9.566(0.7 \%)$ lightning strikes were analyzed over the study period 01-02-2008 to 11-02-2017, a total of $4.832(0.3 \%)$ lightning strikes were analyzed over the study period 01-03-2008 to 30-03-2017, a total of 16.621 (1.2\%) lightning strikes were analyzed over the study period 01-04-2008 to 30-04-2017, a total of 148.810 (10.5\%) lightning strikes were analyzed over the study period 06-05-2008 to 27-05-2017, a total of 287.860 (20.3\%) lightning strikes were analyzed over the study period 01-062008 to 11-06-2017, a total of $433.846(30.6 \%)$ lightning strikes were analyzed over the study period 01-07-2008 to 31-07-2017, a total of 256.677 (18.1\%) lightning strikes were analyzed over the study period $01-08-2008$ to $29-08-2017$, a total of $171.590(12.1 \%)$ lightning strikes were analyzed over the study period 01-09-2008 to 30-09-2017, a total of $34.763(2.5 \%)$ lightning strikes were analyzed over the study period $01-10-2008$ to 30 $10-2017$, a total of 26.763 (1.9\%) lightning strikes were analyzed over the study period 01-11-2008 to 30-11-2017, a total of 20.139 (1.4\%) lightning strikes were analyzed over the study period 01-12-2008 to 29-12-2016. All these analyses are presented in Figure 7. The most active lightning month is July, the second most active lightning month is June and the less active month is March. 


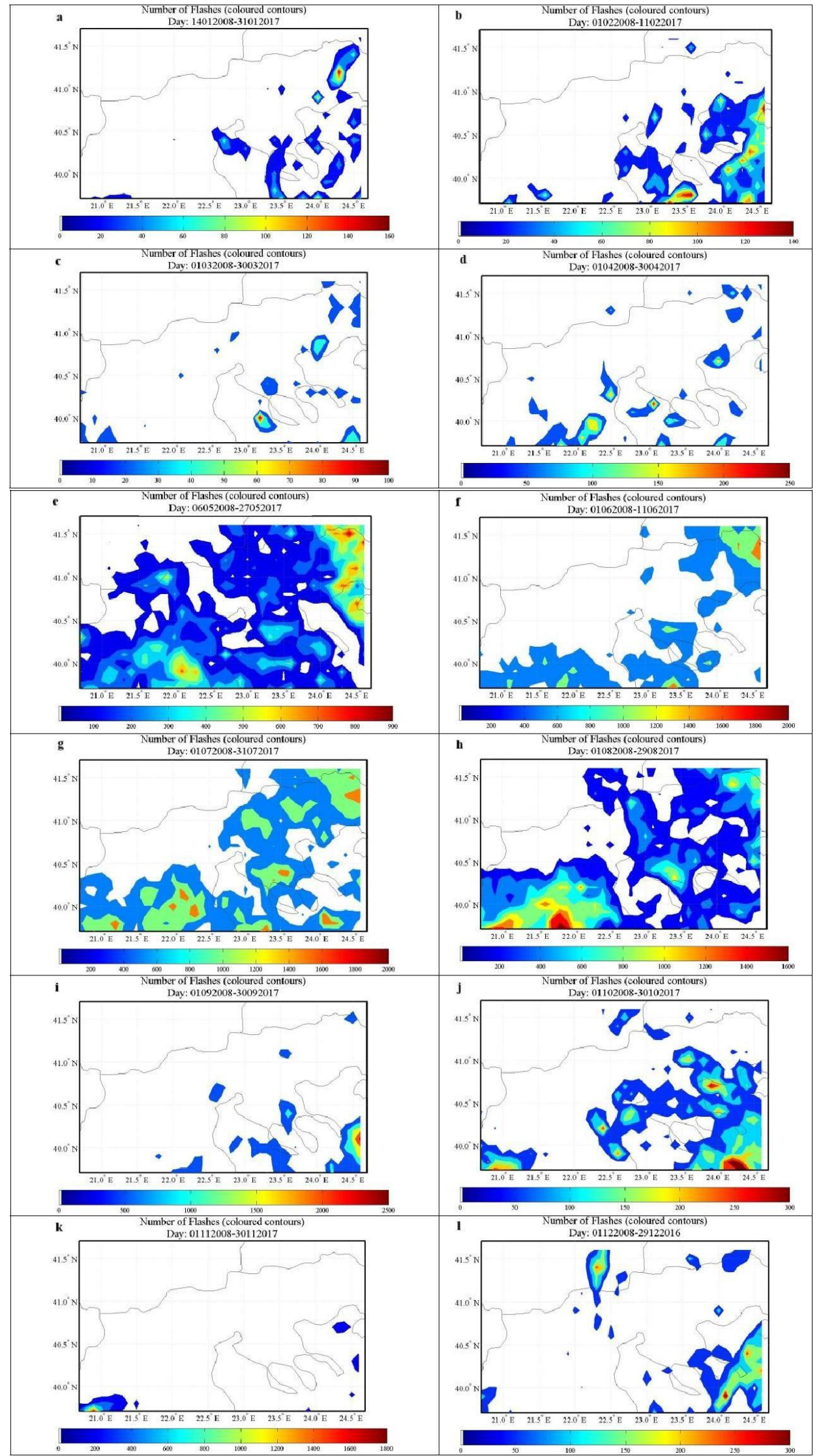

Figure 7: Monthly total lightning density for: a) January, b) February, c) March, d) April, e) May, f) June, g) July, h) August, i) September, j) October, k) November, 1) December. 
In January, February and March, the regions with the highest lightning activity are the waters and the coastlines of the Gulf of Thermaikos and the Gulf of Strimonikos. The lack of surface heating over land maintains thunderstorms over warmer waters, where there is also more available moisture and convergence. In April, convection begins to take place over land due to the surface heating and the mountain of Olympus shows an increase in lightning activity. In May, there is a reverse in lightning activity and the maxima appear over land, and especially over the mountainous regions. Also,

western Macedonia reveals the highest lightning density among all the other months. It seems that there is enough instability, since the Etesian winds are not well established and the land begins to get warmer than the above boundary layer. In June, July and August, western Macedonia reveals minor lightning activity in relation to other regions, in which lightning activity has almost doubled. In September and October, there is a very sharp decrease of lightning activity over land. In November, lightning densities decrease over water also, and in December the distribution of higher lightning densities shifts over water and coastlines as in January, February and March. These results are in good agreement with earlier studies of lightning densities across Europe [3].

\section{Warm period total lightning and total positive lightning density}

A total of $1.315 .403(92.8 \%)$ lightning strikes were analyzed over the study period 0104-2008 to 30-09-2017, a total of 51.422 (87.4\%) lightning strikes were analyzed over the study period 02-04-2008 to 30-09-2017. All these analyses are presented in Figure 8.

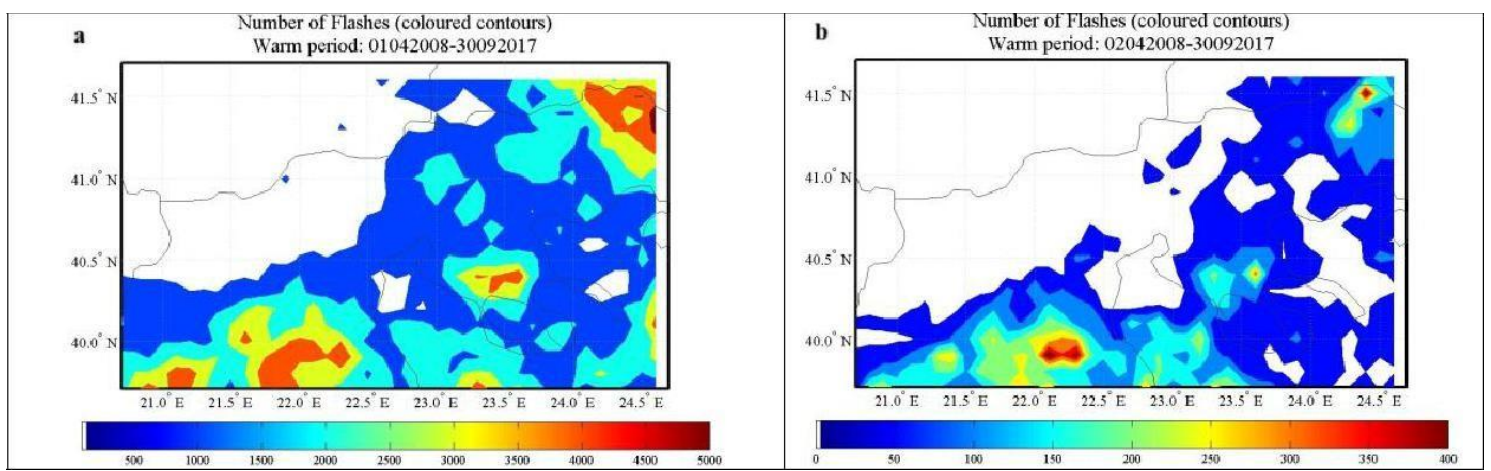

Figure 8. Warm period lightning density for: a) total lightning and b) total positive lightning.

In the warm period (April-September) the mountainous regions display the highest total lightning densities and the highest total positive lightning densities. Western Macedonia holds the minima lightning densities and also there is an obvious contrast between land and the northwest Aegean Sea.

\section{Cold period total lightning density and total positive lightning density}

A total of $101.531(7.2 \%)$ lightning strikes were analyzed over the study period 14-012008 to 29-12-2016, a total of 7.386 (12.6\%) lightning strikes were analyzed over the study period 14-01-2008 to 29-12-2016. All these analyses are presented in Figure 9. In the cold period (October-March) the northwest Aegean Sea and coastlines of Chalkidiki display the highest total lightning densities and the highest total positive lightning densities. Also, some remnants of lightning activity appear in south and west borders between Thessaly and Hpeiro. 


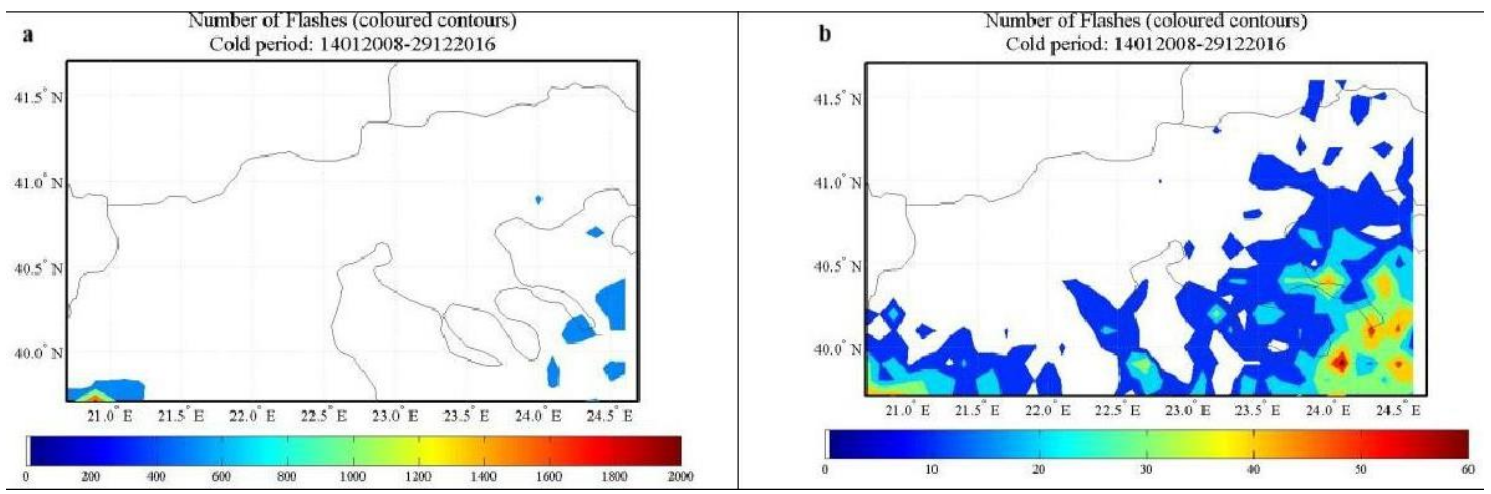

Figure 9. Cold period lightning density for: a) total lightning and b) total positive lightning.

\section{DISCUSSION AND CONCLUSIONS}

The analysis of the lightning strike distributions across Macedonia reveals that during spring and summer thunderstorms are favoured mostly over mountainous regions, except for the west part, which experience actually the lowest lightning activity. During the warm period there is a positive relationship of lightning activity with elevation [8]. Also, this study revealed that in May, the convection is indicated mostly above land, while in the previous months is mostly sea-based. In September, convection is displaced again over sea and only some remnants appear over land. During the cold period the lightning activity is more intense above sea and especially during autumn. That is, the number of lightning strikes is positively correlated with the warmer sea during autumn [9]. The effects of unusually strong storms appear in the lightning density plots, which will be further studied in the future.

Finally, this study revealed different thunderstorm regimes from which lightning risk areas can be derived. In warm period, the mountainous areas, especially Olympus, Holomontas, Falakro and surrounding areas, and in cold period the Gulf of Thermaikos, the Gulf of Strimonikos and the coastlines of Chalkidiki experience high lightning activity, with the consequence to be described as high risk areas.

\section{REFERENCES}

[1] A. Papadopoulos, E. Serpetzoglou and E. Anagnostou. Evaluating the impact of lightning data assimilation on mesoscale model simulations of a flash flood inducing storm, Atmospheric research, Vol. 94, Issue 4, pp 715-725.

[2] E. Galanaki, V. Kotroni, K. Lagouvardos and A. Argiriou. A ten-year analysis of cloud-toground lightning activity over the eastern Mediterranean region, Atmospheric Research, Vol. 166, Issue 1, pp 213-222.

[3] G. Anderson and D. Klugmann. A European lightning density analysis using 5 years of ATDnet data, Natural Hazards and Earth System Science, Vol.14, Issue 4, pp 815-829.

[4] Ken Dixon, Clifford F. Mass, Gregory J. Hakim and Robert H. Holzworth. The Impact of Lightning Data Assimilation on Deterministic and Ensemble Forecasts of Convective Events, Journal of Atmospheric and Oceanic Technology, vol. 33, issue 9, pp 1801-1823;

[5] N. Mazarakis, V. Kotroni, K. Lagouvardos and A. Argiriou. Storms and lightning activity in Greece during the warm periods of 2003-2006, Journal of Applied Meteorology and Climatology, Vol.47, Issue 12, 3089-3098. 
[6] P. Nastos, I. Matsangouras and T. Chronis. Spatio-temporal analysis of lightning activity over Greece - Preliminary results derived from the recent state precision lightning network, Atmospheric Research, Vol. 144, pp 207-217.

[7] Themis G. Chronis. Preliminary Lightning Observations over Greece, Journal of Geophysical Research, vol. 117, Issue D3.

[8] V. Kotroni and K. Lagouvardos. Lightning occurrence in relation with elevation, terrain slope, and vegetation cover in the Mediterranean, Journal of Geophysical Research, Vol.113, Issue D21.

V. Kotroni and K. Lagouvardos. Lightning in the Mediterranean and its relation with sea-surface temperature, Environmental Research Letters, Vol. 11, Number 3. 